\title{
Peramalan Jumlah Penjualan Menggunakan Jaringan Syaraf Tiruan Backpropagation Pada Perusahaan Air Minum Dalam Kemasan
}

\author{
http://dx.doi.org/10.28932/jutisi.v5i2.1607
}

\author{
Nur Fitrianingsih Hasan ${ }^{凶}{ }^{\# 1}$, Kusrini ${ }^{* 2}$, Hanif Al Fatta ${ }^{\# 3}$ \\ ${ }^{I}$ Magister Teknik Inormatika, Universitas AMIKOM Yogyakarta \\ Jalan Ring Road Utara, Condong Catur, Sleman, Yogyalarta, Telp: (0274) 884201 - 207 \\ 1 \\ ${ }^{2}$ Magister Teknik Inormatika, Universitas AMIKOM Yogyakarta \\ Jalan Ring Road Utara, Condong Catur, Sleman, Yogyalarta, Telp: (0274) $884201-207$ \\ 2 kusriniaamikom.ac.id \\ ${ }^{3}$ Magister Teknik Inormatika, Universitas AMIKOM Yogyakarta \\ Jalan Ring Road Utara, Condong Catur, Sleman, Yogyalarta, Telp: (0274) 884201 - 207 \\ 3 hanif.a@amikom.ac.id
}

\begin{abstract}
The inhibition of the production and distribution of bottled water has become a serious problem in survival community and company, so a solution is needed for this problem, both short and long term solutions. One of the things that can be done by the company or management is the right amount of production and distribution by estimating sales. Estimated sales are the process of predicting which products will be sold in the future based on data that ever happened. This paper aims to determine the level of accuracy of Backpropagation ANN in estimating the sale of bottled drinking water. The ANN architecture used is 12-10-1 with MSE value 0,00043743 and MAPE value $6.88 \%$. There is a difference from the actual data with the forecasting result which is equal to $2 \%$ but this is normal because in forecasting activities, the results are an approach.
\end{abstract}

Keywords - Artificial Neural Network, Backpropagation, Bottled Water, Sales Forecasting.

\section{Pendahuluan}

Air merupakan kebutuhan hidup yang paling penting. Kebutuhan akan air bersih yang dapat dikonsumsi harus melalui tahap pengelolaan yang baik[1]. Dalam memenuhi kebutuhan air minum yang aman untuk di konsumsi, masyarakat pada umumnya mendapatkannya dari 2 sumber yaitu air yang dimasak / diolah sendiri dan air minum dalam kemasan (AMDK)[2].

Berdasarkan keputusan Menteri Perindustrian Republik Indonesia Nomor 11/M-IND/PER/3/2017 telah memberikan definisi yang jelas mengenai AMDK, yaitu air yang telah diproses tanpa bahan pangan lainnya dan bahan tambahan pangan, dikemas, dan aman untuk diminum. Seiring dengan meningkatnya jumlah penduduk dari tahun ke tahun, tentunya kebutuhan AMDK akan semakin meningkat. Menurut Asosiasi Perusahaan Air Minum dalam Kemasan Indonesia atau ASPADIN (2015), pada tahun 2014 masyarakat Indonesia mengkonsumsi 23,1 miliar liter air minum dalam kemasan untuk dikonsumsi, jumlah tersebut meningkat $11,3 \%$ dari permintaan di tahun 2013 yang hanya sebesar 20,48 miliar liter air per tahun [3].

Perusahaan Air Minum ABC yang berada di Kota Jayapura merupakan salah satu BUMD di Jayapura yang mengelola dan mendistribusikan Air. Perusahaan ABC memiliki salah satu unit bisnis yang berkonsentrasi pada produksi dan pendistribusian AMDK. Sumber air yang digunakan Perusahaan ABC saat ini semuanya merupakan air permukaan atau air sungai. Sumber air tersebut memiliki daerah tangkapan air di pegunungan Cyclop, Sentani. Namun sejak 2018, secara kapasitas terjadi penurunan debet air terutama pada musim kemarau, tetapi jika masuk musim hujan justru terjadi peningkatan kekeruhan air. Produksi AMDK kemudian ikut tergangun karena banjir bandang yang baru saja terjadi di Sentani awal tahun 2019, beberapa pipa saluran air milik Perusahaan $\mathrm{ABC}$ mengalami kerusakan sehingga produksi dan pendistribusian AMDK menjadi terhambat, sehingga perlu adanya langkah solusi untuk masalah ini baik solusi jangka pendek maupun jangka panjang. 
Salah satu yang dapat dilakukan perusahaan ataupun pihak manajemen agar jumlah produksi dan pendistribusian tepat adalah dengan melakukan forecasting sales (peramalan penjualan). Peramalan adalah seni dan ilmu memprediksi peristiwa-peristiwa yang akan terjadi dengan menggunakan data historis dan memproyeksikannya ke masa depan dengan beberapa bentuk model matematis[4]. Peramalan penjualan merupakan proses aktivitas memperkirakan porduk yang akan dijual di masa mendatang dalam keadaan tertentu dan di buat berdasarkan data yang pernah terjadi dan mungkin akan terjadi [5].

Banyak teknik dan metode yang diterapkan dalam proses peramalan. Dalam melakukan peramalan diperlukan perhitungan yang akurat sehingga diperlukan peramalan yang tepat [6]. Metode Jaringan Syaraf Tiruan (JST) dengan algoritma Backpropagation dalam ilmu AI dapat diterapkan untuk meramal penjualan dengan menentukan arsiterktur jaringan yang tepat sehingga hasil peramalaan dapat mendekati nilai aktual. Jaringan perambatan galat mundur (backpropagation) merupakan salah satu algoritma JST yang dapat digunakan dalam menyelasaikan masalahmasalah rumit berkaitan dengan identifikasi, peramalan, pengenalan pola dan sebagainya.

Pada penelitian sebelumnya JST Backpropagation digunakan dalam meramal penjualan pada perusahaan retail [7], meramalkan penjualan mobil menggunakan JST Backpropagation dan di kombinasikan dengan validasi Certainty Factor[8], penerapan JST Backpropagation untuk meramal penjualan Coklat dan membandingkan hasil permalan dengan data testing dan peramalan dengan data time series hasilnya lebih baik dengan data testing JST Backpropagation[9], memprediksi jumlah produksi daging sapi menggunakan JST Backpropagation[10].

Penelitian yang akan dilakukan bertujuan untuk mengetahui tingkat akurasi dari penggunaan JST Backpropagation dalam meramal penjualan AMDK pada Unit Bisnis AMDK Perusahaan ABC Kota Jayapura menggunakan JST Backpropagation. Data yang dijadikan sebagai data prediksi adalah data penjualan produk AMDK 600ml tahun 2017-2018. Data penjualan tahun 2017 digunakan untuk data training kemudian data tahun 2018 digunakan sebagai data testing. Testing dilakukan untuk menguji arsitektur yang dipilih untuk peramalan. Arsitektur yang digunakan adalah arsitektur peramalan penjualan AMDK yang telah dilakukan analisis pada penelitian [11] yang menghasilkan arsitektur terbaik untuk peramalan penjualan AMDK.

Hasil penelitian ini diharapkan dapat menghasilkan peramalan yang baik sehingga dapat digunakan Unit Binis AMDK Perusahaan ABC Kota Jayapura sebagai dasar dalam pengambilan keputusan untuk menentukan jumlah produksi AMDK.

\section{Metode PENELITIAN DAN LANDASAN TEORI}

Pada penelitian ini dilakukan beberapa tahapan penelitian dimulai dari identifikasi masalah, Studi litertur yaitu mencari teori-teori yang mendukung untuk penelitian ini, mengumpulkan data penelitian dan melakukan analisa terhadap data training dan testing untuk kebutuhan peramalan penjualan dengan algoritm backpropagation. Berikut alur penelitian dapat dilihat pada gambar 1.

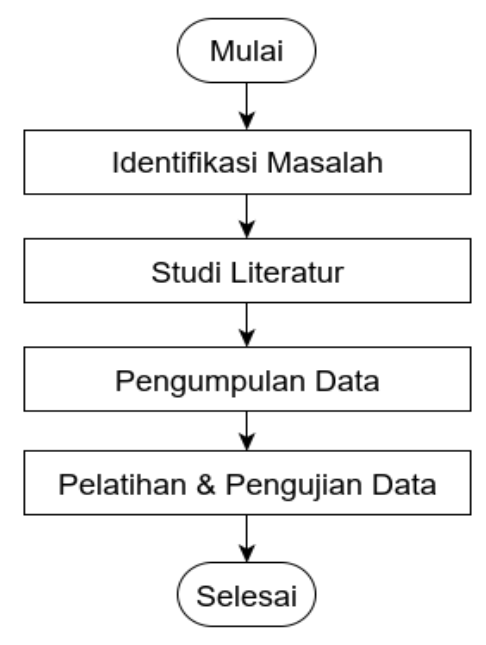

Gambar 1. Alur Penelitian

Dalam penelitian ini terdapat beberapa teori yang menjadi landasan yaitu mengenai peramalan penjualan dan semua pembahasan teori, aplikasi, serta tahapan dalam metode JST Backpropagation.

\section{A. Peramalan Penjualan}

Peramalan penjualan merupakan proses aktifitas memperkirakan produk yang akan dijual di masa mendatang dalam keadaan tertentu dan di buat berdasarkan data yang pernah terjadi atau data masa lalu[5].

Banyak teknik dan metode yang diterapkan dalam proses peramalan. Banyak teknik dan metode peramalan. Dalam melakukan peramalan diperlukan perhitungan yang akurat sehingga diperlukan peramalan yang tepat [6]. Metode peramalan di bagi menjadi 2 yaitu metode statistika dan metode jaringan syaraf. Terdapat 2 pendekatan untuk melakukan peramalan yaitu dengan pendekatan kualitatif dan pendekatan kuantitatif [12].

\section{B. Jaringan Syaraf Tiruan}

Definisi jaringan syaraf tiruan (JST) menurut [13], JST adalah system komputasi dimana arsitektur dan operasi diilhami dari pengetahuan tentang sel syaraf biologis di dalam otak manusiia. JST dapat digambarkan sebagai sebagai model matematis dan komputasi untuk fungsi aproksimasi nonlinear, klasifikasi data, cluster, prediksi dan regrasi. Menurut [14] dengan kemampuan JST yang sangat baik, beberapa aplikasi JST memang sangat cocok untuk 
diterapkan pada kasus klasifikasi, asosiasi, prediksi, optimasi dan self-organizing.

JST juga merupakan pemodelan data yang kuat yang mampu menangkap dan mewakili hubungan input-output yang komplek, karena kemampuannya untuk memecahkan beberapa masalah relatif mudah digunakan, ketahanan untuk menginput data kecepatan untuk eksekusi dan menginisialisasikan system rumit[15].

Konsep JST menurut [16] bisa dilihat dari kerangka kerja JST yaitu dilihat dari jumlah lapisan layer dan jumlah node pada setiap lapisan. Lapisan-lapisan penyusun JST dapat dibagi menjadi tiga yaitu lapisan input, lapisan hidden dan lapisan output. Ada beberapa arsitektur JST di antaranya Jaringan Single Layer dan Jaringan Multi-Layer.

1) Jaringan Single Layer

Jaringan yang memiliki arsitektur jenis inihanya memiliki satu bah lapisan bobot koneksi, jaringan ini terdiri dari unitunit input yang menerima sinyal dari luar dan unit-unit output dimana kita bisa membaca respon dari JST tersebut. Adapun gambar untuk jaringan single layer dapat dilihat pada gambar 2 .

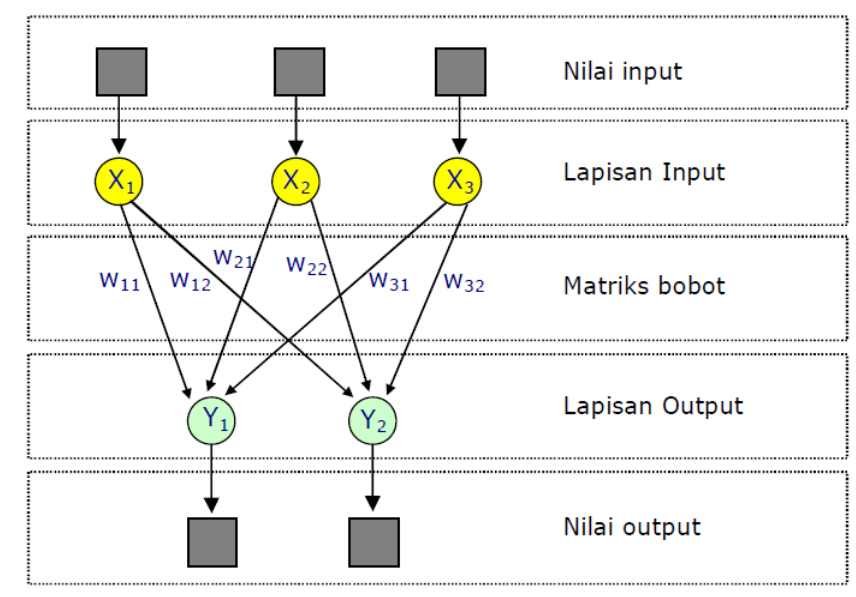

Gambar 2. Jaringan Single Layer

\section{2) Jaringan Multi-Layer}

Merupakan jaringan dengan satu atau lebih lapisan tersembunyi. Multi-layer ini memiliki kemampuan lebih dalam memecahkan masalah bila dibandingkan dengan single layer. Namun jaringan multi-layer dalam pelatihannya jauh lebih rumit, adapun gambar arsitektur jaringan multi-layer dapat dilihat pada gambar 3.

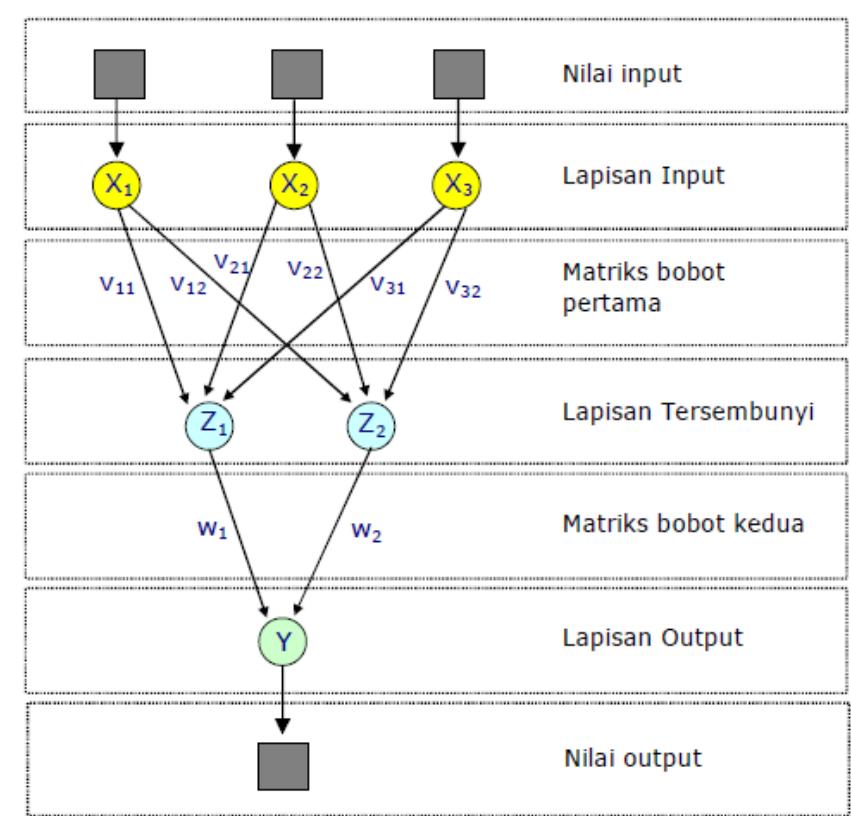

Gambar 3. Jaringan Multi-Layer

\section{Fungsi Aktivasi}

Fungsi aktivasi merupakan bagian penting dalam tahapan perhitungan keluaran dari suatu algoritma. Beberapa fungsi aktivasi yang digunakan dalam JST adalah :

1. Fungsi identitas $f(\mathrm{x})=\mathrm{x}$, untuk semua $\mathrm{x}$ (1)

2. Fungsi undak biner (dengan batas ambang)

$$
f(x)=\left\{\frac{1 \text { untuk } x \geq \theta}{0 \text { untuk } x<\theta}\right\}
$$

3. Fungsi sigmoid

$$
\begin{aligned}
& f(x)=\frac{1}{1+\exp (-\sigma x)} \ldots \ldots \ldots \ldots \ldots \\
& f^{\prime}(x)=\sigma f(x)[1-f(x)
\end{aligned}
$$

4. Fungsi sigmoid bipolar

$$
\begin{aligned}
& g(x)=2 f(x)-1=\frac{2}{1+\exp (-\sigma x)} \ldots \ldots \ldots \ldots \ldots \ldots \ldots \ldots \ldots \ldots \ldots \ldots \ldots \ldots \ldots \ldots \ldots \\
& =
\end{aligned}
$$

\section{Daftar Istilah dan Notasi Dalam Jaringan Syaraf Tiruan}

Beberapa istilah-istilah jaringan syaraf tiruan yang sering ditemui dapat dilihat pada TABEL I [17].

TABEL I

DAFTAR ISTILAH JST

\begin{tabular}{|l|l|}
\hline Isitilah & \multicolumn{2}{|c|}{ Keterangan } \\
\hline Neuron, node, unit & $\begin{array}{l}\text { Sel saraf tiruan yang merupakan } \\
\text { elemen pengolahan jaringan syaraf }\end{array}$ \\
& tiruan. Setiap neuron menerima data \\
input, memproses input tersebut \\
(melakukan sejumlah perkalian dengan
\end{tabular}




\begin{tabular}{|c|c|}
\hline Isitilah & Keterangan \\
\hline & $\begin{array}{l}\text { melibatkan fungsi aktivasi), dan } \\
\text { mengirimkan hasilnya berupa sebuah } \\
\text { output. }\end{array}$ \\
\hline Jaringan & $\begin{array}{l}\text { Kumuplan neuron yang saling } \\
\text { terhubung dan membentuk lapisan. }\end{array}$ \\
\hline $\begin{array}{l}\text { Input atau } \\
\text { masukkan }\end{array}$ & $\begin{array}{l}\text { Berhubungan dengan sebuah atribut } \\
\text { tunggal dari sebuah pola atau data lain } \\
\text { dari dunia luar. Sinyal-sinyal input ini } \\
\text { kemudian diteruskan ke lapisan } \\
\text { selanjutnya. }\end{array}$ \\
\hline $\begin{array}{l}\text { Lapisan } \\
\text { tersembunyi (Hiden } \\
\text { Layer) }\end{array}$ & $\begin{array}{l}\text { Lapisan yang tidak secara langsung } \\
\text { berinteraksi dengan dunia luar. } \\
\text { Lapisan ini memperluas kemampuan } \\
\text { jaringan syaraf tiruan dalam } \\
\text { menghadapi } \\
\text { kompleks. }\end{array}$ \\
\hline Bobot & $\begin{array}{l}\text { Bobot dalam jaringan syaraf tiruan } \\
\text { merupakan nilai matematis dari } \\
\text { koneksi, yang mentransfer jaringan } \\
\text { dari satu ke lapisan lainnya. Bobot ini } \\
\text { digunakan untuk mengatur jaringan } \\
\text { sehingga jaringan syaraf tiruan bisa } \\
\text { menghasilkan output yang diinginkan } \\
\text { sekaligus bertujuan membuat jaringan } \\
\text { tersebut belajar. }\end{array}$ \\
\hline $\begin{array}{l}\text { Fungsi aktivasi, } \\
\text { fungsi transfer }\end{array}$ & $\begin{array}{l}\text { Fungsi yang menggambarkan } \\
\text { hubungan antara tingkat aktivasi yang } \\
\text { berbentuk linear atau nonlinear. } \\
\text { Beberapa fungsi aktivasi jaringan } \\
\text { syaraf tiruan yaitu Hard linit, Purelin } \\
\text { dan Sigmoid.Yang popular digunakan } \\
\text { saat ini adalah fungsi sigmoid yang } \\
\text { memiliki beberapa varian yakni } \\
\text { sigmoid logaritma, sigmoid biner, } \\
\text { sigmoid bipolar dan sigmoid tangent. }\end{array}$ \\
\hline Aturan kerja & $\begin{array}{l}\text { Secara umum aturan kerja dari teknik } \\
\text { algoritma jaringan syaraf tiruan ada } 4 \text {, } \\
\text { yaitu aturan error correcting, aturan } \\
\text { Boltzman, aturan Hebbbian dan aturan } \\
\text { kompetitif }\end{array}$ \\
\hline
\end{tabular}

Notasi yang sering dipakai dalam Jaringan Syaraf Tiruan menggunakan beberapa notasi yan berguna dalam pembuatan algoritma pembelajaran backpropagation antara lain dapat dilihat pada TABEL II berikut ini:

TABEL II

DAFTAR NOTASI DALAM JST

\begin{tabular}{|c|l|}
\hline Notasi & \multicolumn{1}{|c|}{ Keterangan } \\
\hline $\mathrm{x}_{\mathrm{i}}, \mathrm{y}_{\mathrm{j}}$ & $\begin{array}{l}\text { Aktivitas dari unit } \mathrm{x}_{\mathrm{i}}, \mathrm{y}_{\mathrm{j}} \text { untuk unit input } \mathrm{x}_{\mathrm{i}}, \mathrm{x}_{\mathrm{i}}= \\
\text { sinyal input, sedangkan unit } \mathrm{y}_{\mathrm{j}}, \mathrm{y}_{\mathrm{j}}=\mathrm{f}_{\left(\mathrm{y} \_\mathrm{in}\right.} \mathrm{j}_{\mathrm{j}}\end{array}$ \\
\hline $\mathrm{W}_{\mathrm{ij}}$ & Bobot koneksi dari unit $\mathrm{x}_{\mathrm{i}}$ ke unit $\mathrm{y}_{\mathrm{i}}$ \\
\hline $\mathrm{b}_{\mathrm{j}}$ & Bisa unit $\mathrm{y}_{\mathrm{j}}$ \\
\hline
\end{tabular}

\begin{tabular}{|c|c|}
\hline Notasi & Keterangan \\
\hline$Y_{-}$in $_{\mathrm{j}}$ & Input jaringan ke unit $\mathrm{y}_{\mathrm{j}} y_{i n j}=b j+\sum_{\mathrm{i}} x i w i j$ \\
\hline $\mathrm{W}$ & Bobot matriks $\mathrm{W}=\left\{\mathrm{w}_{\mathrm{ij}}\right\}$ \\
\hline $\mathrm{W}_{\mathrm{ij}}$ & Vector bobot $\mathrm{w}_{\mathrm{ij}}=\left(\mathrm{w}_{1 \mathrm{j}}, \mathrm{w}_{2 \mathrm{j}}, \ldots \mathrm{wnj}^{\mathrm{T}}\right.$ \\
\hline$\|\mathrm{x}\|$ & Vector $\mathrm{X}$ \\
\hline$\theta j$ & $\begin{array}{l}\text { Threshold untuk aktivasi neuron } \mathrm{y} \text {, jika input } \\
\text { yang masuk ke jaringan lebih besar dari nilai } \\
\text { threshold, maka fungsi aktivasi }=1 \text {, sebaliknya } \\
\text { fungsi aktivasi }=0\end{array}$ \\
\hline $\mathrm{S}$ & Pelatihan vector input $\mathrm{S}=\left(\mathrm{S}_{1}, \mathrm{~S}_{2}, \ldots \mathrm{S}_{\mathrm{n}}\right)$ \\
\hline $\mathrm{T}$ & $\begin{array}{l}\text { Pelatihan vector output atau target } \mathrm{t}=\left(\mathrm{t}_{1}, \mathrm{t}_{2},\right. \\
\left.\text {... } \mathrm{t}_{\mathrm{n}}\right)\end{array}$ \\
\hline $\mathrm{X}$ & Vector input $\mathrm{x}=\left(\mathrm{x}_{\mathrm{i}}, \mathrm{x}_{2}, \ldots \mathrm{x}_{\mathrm{n}}\right)$ \\
\hline "wij & Perubahan dalam $w_{i j}$ “ $w_{i j}=w_{i j}$ baru $-w_{i j}$ lama \\
\hline$\propto$ & $\begin{array}{l}\text { Tingkat pembelajaran (lerning rate). Learning } \\
\text { rate akan mengawasi atau mengontrol bobot } \\
\text { dalam setiap kali pembelajaran }\end{array}$ \\
\hline
\end{tabular}

\section{E. Algoritma Backpropagation}

Backpropagation merupakan algoritma pembelajaran yang terawasi (supervised learning) dan biasanya digunakan oleh perceptron dengan banyak lapisan untuk mengubah bobot-bobot yang terhubung dengan neuron-neuron yang ada pada lapisan tersembunyi[18]. Backpropagation termasuk ke dalam arsitektur jaringan multi-layer.

Backpropagation menggunakan error output untuk mengubah nilai bobot-bobotnya dalam arah mundur (backward). Untuk mendapatkan error ini, tahap perambatan maju (feedforward) harus dikerjakan terlebih dahulu[7]. Untuk memudahkan pemahaman lihat gambar 4. 


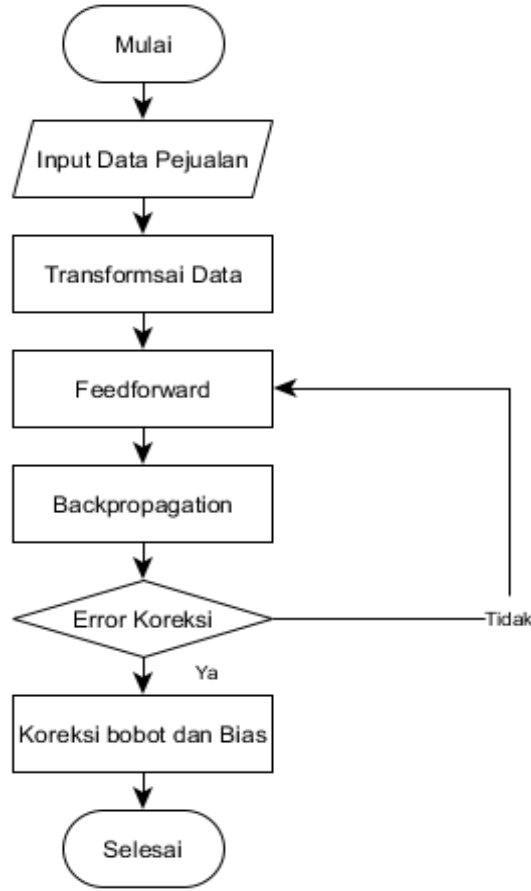

Gambar 4. Flowchart alur Backpropagation

Dilihat pada gambar 4 secara garis besar proses peramalan dengan JST Backpropagation dilakukan dalam 3 langkah besar yaitu Feedforward, backpropagation dan update bobot juga bias. Dalam perhitungannya secara manual menggunakan beberapa rumus untuk porses pelatihan. Seperti yang telah dijelaskan sebelumnya, Dalam tahapan pelatihan backpropagation ini meliputi 3 fase yaitu : 1) Fase pertama Feedforward

Untuk masing-masing pasangan training lakukan proses feedforward dengan 3 langkah.

Langkah 1: Masing-masing unit input (Xi, i-1,..,n) menerima sinyal input $\mathrm{Xi}$ dan menyebarkan ke sinyal unit lapisan atas (hidden unit).

Langkah 2 : Masing-masing unit tersembunyi $(\mathrm{Zj}, \mathrm{j}=, \ldots, \mathrm{p})$ menggunakan persamaan (8) menjumlahkan bobot sinyal input $\mathrm{z} \_\mathrm{in}_{\mathrm{j}}=v_{0 j}+\sum_{i} x_{i} v_{i j}$

dan mengaplikasikan fungsi aktifasi untuk menghitung sinyal output menggunakan persamaan $(9) \mathrm{z}_{j}=f\left(\mathrm{z}_{-} \mathrm{in}_{j}\right) \ldots . .(9)$ dan mengirimkan sinyal tersebut ke semua unit $\mathrm{p}$ ada lapisan atasnya (unit output).

Langkah 3: Masing-masing unit output ( $\mathrm{Yk}, \mathrm{k}=, \ldots, \mathrm{m})$ menggunakan persamaan (10) menjumlahkan jumlah sinyal input $\mathrm{Y} \_\mathrm{in}_{k}=W_{0 \mathrm{k}}+\sum_{i} z_{i} w_{j}$ dan mengaplikasikan fungsi aktifasi persamaan (11) untuk menghitung sinyal output $y_{k}=f\left(\mathrm{y}_{-} \mathrm{in}_{k}\right)$

2) Fase kedua Backporpagation

Untuk masing-masing pasangan training, kemudian lakukan bacpropagation.
Langkah 1 : Masing-masing unit output $(\mathrm{Yk}, \mathrm{k}=, \ldots, \mathrm{m})$ menerima sebuah pola target yang bersesuaian dengan pola training input, menghitung informasi kesalahan menggunakan persamaan $\delta_{k}=\left(t_{k}-y_{k}\right)$ f ' $\left(y_{-} i n_{k}\right)$

kemudian menghitung koreksi bobot (ini digunakan untuk memperbaiki $\mathrm{w}_{j k}$ ) dengan persamaan $\Delta w_{j k}=a \delta_{k}, z_{j} \ldots$ (13) dan akhirnya menghitung korelasi bias (ini digunakan untuk memperbaiki $\mathrm{w}_{o k}$ ) dengan persamaan $\Delta w_{0 k}=a \delta_{k}$

setelah itu mengirimkan $\delta_{k}$ ke unit dalam lapisan paling atas. Langkah 2 : Masing-masing unit yang tersembunyi $(\mathrm{Zj}, \mathrm{j}$ ,..,p) menjumlahkan input delta (dari unit lapisan atas) dengan menggunakan persamaan

$$
\delta_{i n j}=(x+a)^{n}=\sum_{k=1}^{m} \delta_{k} w_{j k}
$$

Kalikan nilai ini dengan turunan fungsi aktivasi untuk menghitung informasi kesalahan menggunaka persamaan $\delta_{j}=\left(\delta_{-} i n_{j \mathrm{f}}{ }^{\prime}\left(Z_{i n j}\right)\right.$

kemudian hitunglah koreksi bobot (digunakan untuk memperbaiki $v_{i j}$ ), dengan menggunakan persamaan yaitu $\Delta V_{i j}=a \delta_{j x}$

Setelah itu hitung koreksi bias (digunakan untuk memperbaiki $v_{o j}$ ) gunakan persamaan

$\Delta V_{0 j}=a \delta_{j}$

3) Fase tiga update bobot dan bias

Setelah itu masuk pada fase memperbaiki bobot dan bias atau memperbarui nilai bobot dan bias. Dengan 2 langkah :

Langkah 1: Masing-masing unit output (Yk, k-,..,m) memperbaiki bobot dan bias $(\mathrm{Zj}, \mathrm{j}-, \ldots, \mathrm{p})$ dengan menggunakan persamaan

$W_{j k}($ baru $)=w_{j k}($ lama $)+\Delta w_{j k}$

kemudian masing-masing unit tersembunyi $(\mathrm{Zj}, \mathrm{j}=, \ldots, \mathrm{p})$ memperbaikit bobot dari bias $(\mathrm{Xi}, \mathrm{i}=1, \ldots, \mathrm{n})$ menggunakan persamaan

$v_{i j}($ baru $)=v_{i j}($ lama $)+\Delta v_{i j}$

Langkah 2: Tes kondisi berhenti

\section{F. Tahap Membentuk Backpropagation Menggunakan $M A T L A B$}

Tahapan yang harus dilakukan untuk implementasi program Backpropagation denngan Matlab adalah dengan 4 tahapan seperti pada gambar 5 yaitu pengumpulan data, transformasi data (pre-processing), pelatihan dan pengujian. 


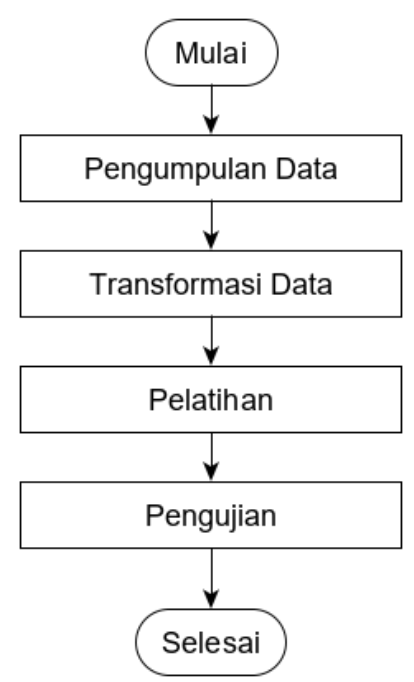

Gambar 5. Tahap implementasi JST dengan Matlab

\section{1) Pengumpulan Data}

Dalam tahap pengumpulan data ini dilakukan identifikasi masalah, kemudian melakukan studi literatur yaitu mencari studi atau penelitian-penelitian dan referensi buku terkait peramalan khususnya peramalan menggunakan metode JST Backpropagation untuk mengetahui lebih lanjut kebutuhan data dalam tahap peneltian selanjutnya. Setelah itu dilakukan pengumpulan data pada perusahaan yang kemudian didapatkan data yang akan digunakan dalam penelitian ini yaitu data penjualan produk AMDK $600 \mathrm{ml}$ tahun 2017-2018. Data penjualan dapat dilihat pada gambar 6.

\begin{tabular}{|c|c|c|c|c|c|c|c|}
\hline & TANGGAL & INVOICE & PRODUCCT & VARIANT & ORDER TYPE & SKU & SOLD QTYCURRENC \\
\hline & 5-Jan-17 & 9050001 & Robong Holo $600 \mathrm{ml}$ & Dus & Distibutor & & 200 IDR \\
\hline & 5-Jan-17 & 9050001 & Robong Holo $330 \mathrm{ml}$ & Dus & Distibutor & & 100 IDR \\
\hline & 5-Jan-17 & 9050001 & Robong Holo $240 \mathrm{ml}$ & Dus & Distibutor & & 350 IDR \\
\hline & 5-Jan-17 & 9050002 & Robong Holo $600 \mathrm{ml}$ & Dus & Distibutor & 030101 & 200 IDR \\
\hline & 5-Jan-17 & 9050002 & Robong Holo $240 \mathrm{ml}$ & Dus & Distibutor & "030106 & 250 IDR \\
\hline ) & 5-Jan-17 & 9050003 & Robong Holo $600 \mathrm{ml}$ & Dus & Distibutor & 030108 & 111 IDR \\
\hline & 6-Jan-17 & $9050 \mathrm{c}$ & Robong Holo $240 \mathrm{ml}$ & Dus & Distibutor & 030113 & 90 IDR \\
\hline ? & 6-Jan-17 & 9050005 & Robong Holo $240 \mathrm{ml}$ & Dus & Distibutor & & 189 IDR \\
\hline & 8-Jan-17 & 9050006 & Robong Holo $600 \mathrm{ml}$ & Dus & Distibutor & 040101 & 200 IDR \\
\hline & 8-Jan-17 & 9050007 & Robong Holo $330 \mathrm{ml}$ & Dus & Distibutor & '040102 & 890 IDR \\
\hline & 9-Jan-17 & 9050008 & Robong Holo $330 \mathrm{ml}$ & Dus & Distibutor & 040103 & 175 IDR \\
\hline & 10-Jan-17 & 9050009 & Robong Holo $240 \mathrm{ml}$ & Dus & Distibutor & 040104 & 200 IDR \\
\hline & 11-Jan-17 & 9050010 & Robong Holo $600 \mathrm{ml}$ & Dus & Distibutor & 040105 & 135 IDR \\
\hline & 11-Jan-17 & 9050011 & Robong Holo $600 \mathrm{ml}$ & Dus & Distibutor & 040106 & 200 IDR \\
\hline & 11-Ian-17 & aกรกก 12 & Rnhnne Holn fnnml & nus & nistihutor & 'nan1ne & $25 \cap \operatorname{InR}$ \\
\hline
\end{tabular}

Gambar 6. Data Penjualan Produk

Dari data penjualan harian pada gambar 6. Kemudian di persiapkan untuk proses normalisasi pada tahap transformasi data.

\section{2) Transformasi Data (Pre-processing)}

Transformasi data dilakukan dengan bantuan software MATLAB R2018a. Data penjualan yang telah didapatkan pada tahapan sebelumnya diolah menjadi data set. Pengolahan data penjualan menjadi data set ini sesuai dengan tahapan yang ada pada JST Backpropagation. Sebelum melakukan proses peramalan, maka data yang sudah ada akan di bagi menjadi dua bagian, yaitu data training dan data testing. Data training merupakan data yang akan digunakan dalam proses pelatihan yaitu data penjualan tahu 2017 bulan Januari-Desember. Adapun data testing adalah data yang digunakan dalam porses peramalan yaitu data penjualan bulan Januari-Desember 2018.

Dalam tahap transformasi data akan dilakukan 2 aktivitas yaitu normalisasi dan perancangan arsitektur jaringan.

a) Normalisasi

Data penjualan yang telah dikumpulkan terlebih dahulu ditransformasikan ke dalam data antara $0-1$ sebelum dilakukan pelatihan dan pengujian dengan JST Backpropagation. Normalisasi bertujuan agar jaringan tidak mengalami kegagalan ketika melakukan pelatihan dan pengujian. Data dinormalisasikan dengan persamaan rumus (21) dalam interval [0-1]. Rumus transformasi data actual untuk di normalisasikan menggunakan rumus:

$X^{\prime}=\frac{0, q(X-a)}{(b-a)}+0,1$

Dimana:

$$
\begin{array}{ll}
X^{\prime} & =\text { Data Normalisasi } \\
\text { X } & =\text { Data Asli } \\
\mathrm{a} & =\text { Nilai data asli minimum } \\
\mathrm{b} & =\text { Nilai data asli maximum }
\end{array}
$$

Sehingga data normalisasi didapatkan seperti pada TABEL III.

TABEL III

NORMALISASI DATA PELATIHAN

\begin{tabular}{|l|c|}
\hline Bulan/Produk & Produk AMDK 600ml \\
\hline Januari & 0.1209 \\
\hline Februari & 0.1000 \\
\hline Maret & 0.1203 \\
\hline April & 0.1405 \\
\hline Mei & 0.1379 \\
\hline Juni & 0.1439 \\
\hline Juli & 0.1415 \\
\hline Agustus & 0.2216 \\
\hline September & 0.4282 \\
\hline Oktober & 0.3286 \\
\hline November & 0.7904 \\
\hline Desember & 0.9000 \\
\hline
\end{tabular}

Hasil normalisasi dalam excel akan dipanggil dan di baca dengan matlab untuk selanjutnya di lakukan pembuatan arsitektur JST menggunakan perintah:

Filename = 'Book1.xlsx';

Sheet $=2$;

xlRange = 'D6:P17';

Data $=$ xlsread(filename, sheet,

xlRange);

data latih $=\operatorname{Data}(:, 1: 12) '$; 
target_latih = Data $(:, 13)^{\prime}$;

$[\mathrm{m}, \mathrm{n}]=$ size (data_latih);

\section{b) Perancangan Arsitektur Jaringan}

Tahap pre-processing selanjutnya adalah perancangan arsitektur jaringan dan menentukan paramter. Jaringan yang digunakan untuk meramal penjualan AMDK memiliki 3 layers yaitu 12 input layer, 11 hidden layer dan 1 output layer. Jumlah hidden layers dan parameter ditentukan dengan cara trial and error. Berdasarkan jumlah neuron input, hidden dan output yang telah ditentukan maka gambar arsitektur JST Backpropagation yang dibentuk akan terlihat seperti pada gambar 7 .

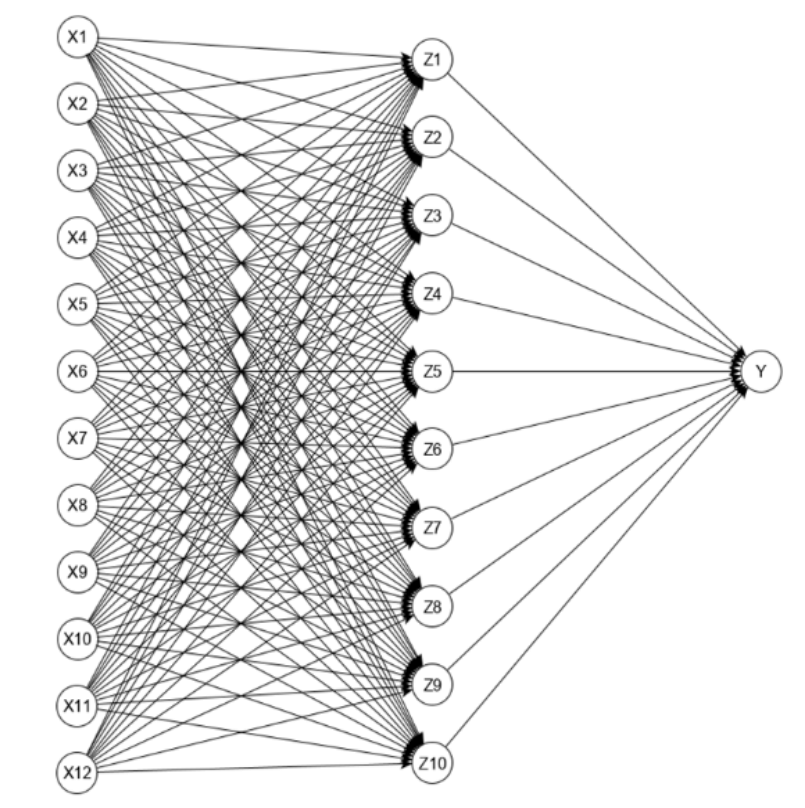

INPUT LAYER

HIDDEN LAYER

OUTPUT LAYER

Gambar 7. Arsitektur JST Backpropagation

Membuat arsitektur JST dan memberikan nilai pada setiap parameter ini sangat berpengaruh selanjutnya dalam proses pelatihan.

\section{3) Pelatihan}

Menggunakan data pelatihan yaitu data penjualan bulan Januari-Desember tahun 2017 dengan menggunakan model arsitektur yang sudah terbentuk, kemudian dilakukan inisialisasi bobot dan parameter dengan perintah newff, kemudian perintah train untuk melatih dan melihat bobot akhirnya. Dengan memberikan nilai yang kita inginkan pada parameter-parameter kita dapat memperoleh hasil yang optimal. Dalam MATLAB perintah net.trainParam.show dipakai untuk menampilkan frekuensi perubahan mse (defaultnya setiap 25 epoch). Perintah net.trainParam.epochs untuk menentukan jumlah epoch atau terasi maksimum pelatihan. Perintah net.trainParam.goal untuk menentukan batas nilai mse agar iterasi dihentikan. Iterasi berhenti jika mse $<$ batas yang ditentukan dalam net.trainParam.goal atau jumlah iterasi mencapai batas yang ditentukan dalam net.trainParam.epochs. Perintah net.trainParam.lr untuk menentukan laju pemahaman (learning rate).

Adapun model arsitektur dan parameter yang digunakan untuk mendapatkan arsitektur terbaik dalam JST dapat dilihat pada TABEL IV.

TABEL IV

MODEL DAN PARAMETER ARSITEKTUR JST BACKPROPAGATION

\begin{tabular}{|c|c|c|c|c|c|}
\hline \multirow{2}{*}{ Arsitektur } & \multicolumn{4}{|c|}{ Parameter } \\
\cline { 2 - 6 } & Ir & Mc & Epoch & Goal & Fungsi Aktivasi \\
\hline $12-10-1$ & 0.1 & 0.9 & 1000 & 0.001 & Logsig \\
\hline
\end{tabular}

4) Pengujian

Pada tahap pengujian data yang menjadi data training dimasukkan ke dalam Matlab. Dalam penelitian ini yaitu data penjualan bulan januari- hingga desember tahun 2018. Setelah mendapatkan hasil JST dilakukan pengujian menggunakan MAPE. MAPE atau Mean Absolute Percentage adalah dengan persamaan rumus[19]:

MAPE $=\frac{\Sigma\left|\left(\frac{X_{t}-F_{t}}{X_{t}}\right)\right|}{n} \times 100 \%$

Setelah mendapatkan hasil simulasi selanjutnya untuk mendapatkan hasil peramalan dilakukan denormalisasi dengan persamaan rumus [20]:

$$
x=\frac{(x-0,1)(b-a)}{0,8}+a
$$

\section{HASIL DAN PEMBAHASAN}

Hasil dari penelitian ini adalah sebuah model arsitektur dengan tingkat akurasi yag terbaik dan hasil peramalan penjualan AMDK.

\section{A. Hasil Pelatihan JST Backpropagation}

Pelatihan data dilakukan beberapa kali trial and error untuk mendapatkan jaringan terbaik dengan menentukan jumlah neuron. Perintah untuk inisialisasi bobot dan parameter pada MATLAB menggunakan instruksi :

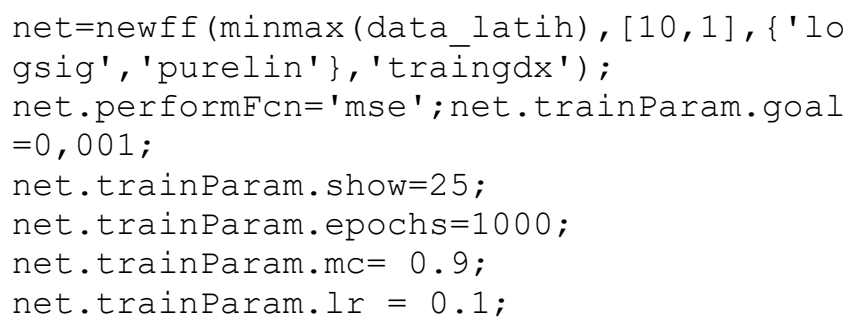

Hasilnya dapat dilihat pada gambar 8 yang merupakan hasil dari arsitektur terbaik. 


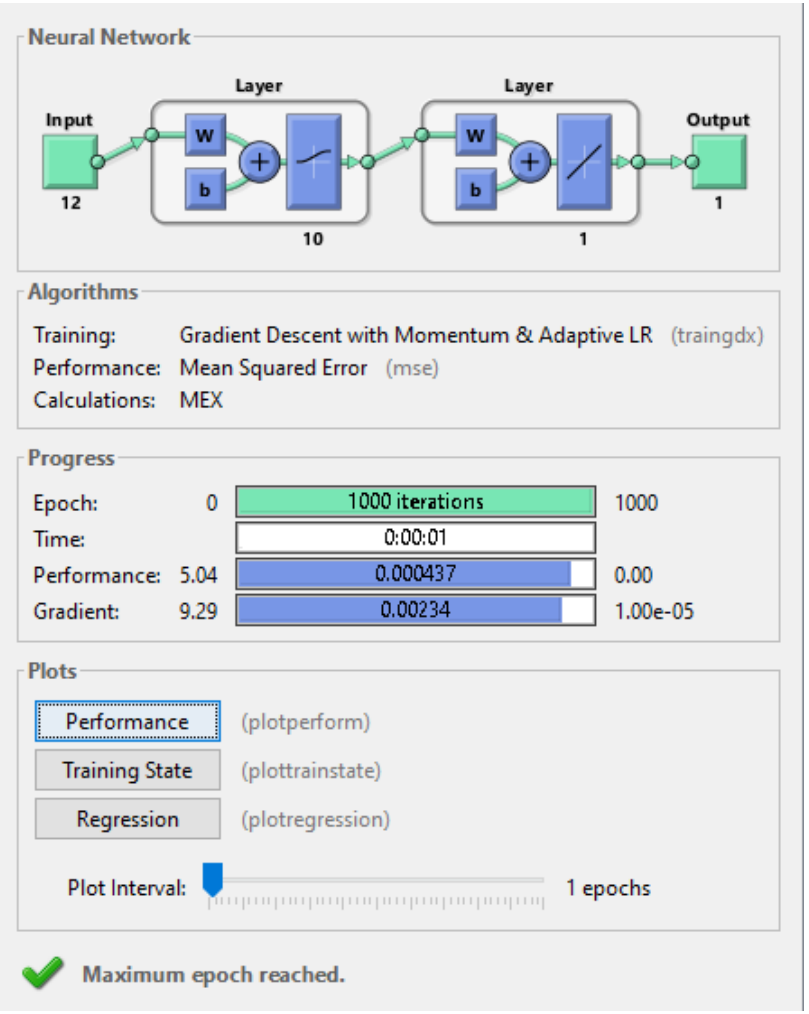

Gambar 8. Model Arsitektur JST Pada Matlab

Pada pengolahan data yang telah didapati berdasarkan pelatihan terbaik berikut beberapa parameter pelatihan yang diatur agar hasil pelatihan optimal.

- Learning rate (lr) bertujuan untuk mempercepat laju iterasinya. Hasil pembahasan untuk $1 r$ ini dimana jika nilai lr terlalu besar maka algoritma menjadi kurang stabil dan mencapai titik minimum local. Jadi errornya adalah nol (0).

- Momentum constant (mc) bertujuan untuk menurunkan gradient dengan momentum dengan memberikan nila 0-1. Untuk mendapatkan error terkecil lr dan mo harus terkoordinasi dengan baik. Tidak ada ketentuan parameter yang pasti untuk mendapatkan error yang kecil. Jadi harus dilakukan beberapa kali percobaan. Dalam penelitian ini menggunakan lr 0,1 dan mc 0,9.

- Epoch (iterasi) bertujuan untuk menunjukkan jumlah iterasi maksimum pada pelatihan. Tidak ada ketentuan berapa nilai iterasi yang harus digunakan. Namun jika terlalu banyak nilai iterasi yang digunakan akan memerlukan aktu yang lama, sebaliknya jika iterasi terlalu sedikit hasil pelatihan akan kurang baik. Dalam penelitian ini menggunakan 1000 tercapai dan mendapatkan hasil yang baik.

- Goal untuk menentukan batas nilai MSE agar iterasi berhenti. Dalam penelitian ini menggunakan goal sebesar 0,001. Jika goal tercapai maka pada grafik performance MSE harus kurang atau sama dengan 0,001. Pada penelitian ini mendapatkan MSE 0,00043743, dapat dilihat pada gambar 9 .

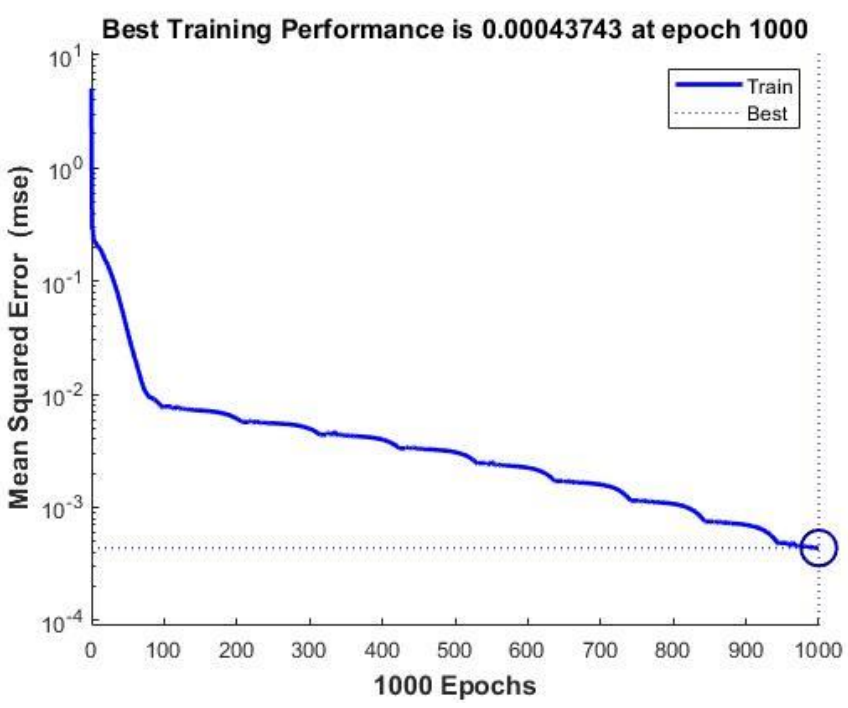

Gambar 9. Performance Model Arsitektur 12-10-1

- Fungsi Aktivasi bertujuan untuk menghubungkan hidden layer ke output layer. Dalam penelitian ini menggunakan fungsi aktivasi fungsi sigmoid biner (logsig) yang umum digunakan dengan range antara 01 .

\section{B. Hasil Pengujian JST Backpropagation}

Hasil pelatihan terbaik diuji dengan data uji yang telah disiapkan menggunakan instruksi:

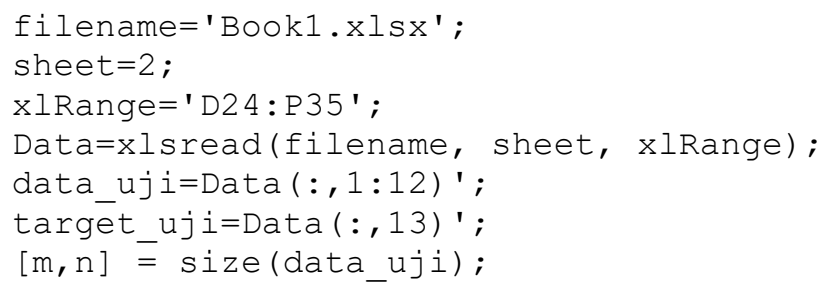

Kemudian pencarian hasil uji JST dengan intruksi :

hasil_uji=sim(net_keluaran,data_uji);

nilai_error=hasil_uji-target_uji,

max dāta $=2590$;

min_data $=169$;

hasil_uji=( (hasil_uji-0.1)* (max_datamin_dāta) /0.8)+min_data;

Hasil pengujian seperti pada gambar 10. 


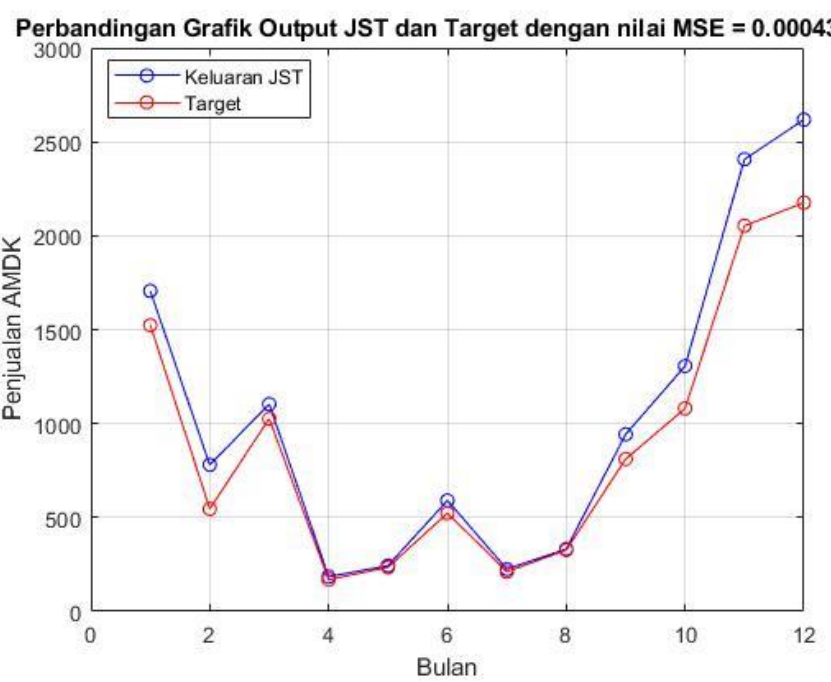

Gambar 10. Perbandingan Output JST dengan JST Pelatihan Data

Hasil pengujian terhadap data latih yaitu dengan menggunakan MSE untuk membandingkan data aktual dengan hasil peramalan JST. Pada Gambar 10 terlihat model hasil JST tidak berbeda jauh dengan data aktual (target)nya. Maka rancangan JST ini ddapat dijadikan model untuk tahap ke pengujian data.

Berikut adalah tabel perbandingan ouput JST dengan pelatihan data (lihat TABEL V).

TABEL V

HASIL PERAMALAN AMDK TAHUn 2019

\begin{tabular}{|c|c|c|c|c|c|}
\hline \multirow{2}{*}{ No. } & \multicolumn{2}{|c|}{ Normalisasi } & \multicolumn{2}{c|}{ Denormalisasi } & \multirow{2}{*}{$\%$} \\
\cline { 2 - 5 } & Target & $\mathbf{Z}$ & Target & $\mathbf{Z}$ & \\
\hline 1 & 0,7721 & 0,7941 & $-0,0220$ & $-0,0285$ & $-2,85$ \\
\hline 2 & 0,7342 & 0,7102 & 0,0240 & 0,0327 & 3,27 \\
\hline 3 & 0,4736 & 0,4908 & $-0,0172$ & $-0,0363$ & $-3,63$ \\
\hline 4 & 0,3502 & 0,3443 & 0,0059 & 0,0168 & 1,68 \\
\hline 5 & 0,2007 & 0,1930 & 0,0077 & 0,0383 & 3,83 \\
\hline 6 & 0,1649 & 0,1472 & 0,0177 & 0,1071 & 10,71 \\
\hline 7 & 0,2615 & 0,2852 & $-0,0237$ & $-0,0904$ & $-9,04$ \\
\hline 8 & 0,1726 & 0,1624 & 0,0102 & 0,0590 & 5,90 \\
\hline 9 & 0,1453 & 0,1613 & $-0,0160$ & $-0,1101$ & $-11,01$ \\
\hline 10 & 0,4170 & 0,3960 & 0,0210 & 0,0504 & 5,04 \\
\hline 11 & 0,2686 & 0,2937 & $-0,0251$ & $-0,0932$ & $-9,32$ \\
\hline 12 & 0,5707 & 0,5005 & 0,0702 & 0,1231 & 12,31 \\
\hline & \multicolumn{5}{|c|}{ MAPE } \\
\hline
\end{tabular}

Pengujian data menggunakan MAPE untuk mengukur validasi jaringan pada kesuluran data didapat sebesar $6,88 \%$. maka tingkat akurasi termasuk sangat baik karena nilanya dibawah $10 \%$.

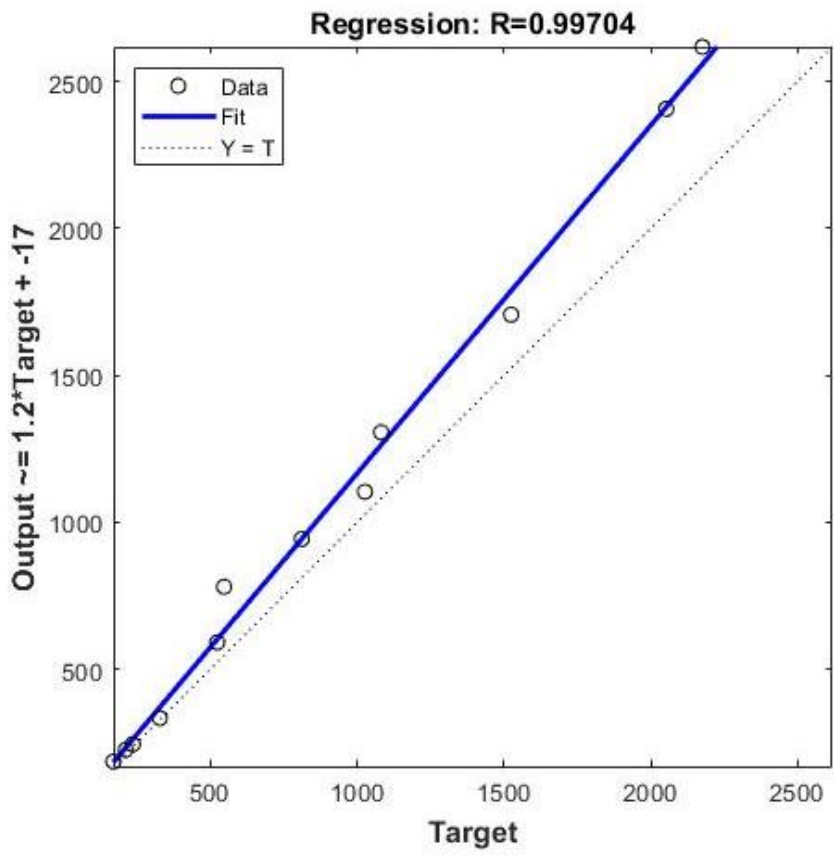

Gambar 11. Hasil Regrsai Data Uji

Pada gambar 11 menunjukkan regresi sebesar 0,9847 yang berarti antara variabel-variabel aktual dengan JST pada pengujian mempunyai korelasi yang baik. Ukuran korelasi sebesar 0,9974 menunjukkan adanya derajat asosiasi yang tinggi. Hasil regrasi pada Gambar 11 juga menunjukkan verifikasi data antara data aktual dengan JST ada perbedaan atau selisih namun tidak begitu signifikan.

\section{Hasil Peramalan Penjualan AMDK}

Setelah didapatkan model arsiterktur yang terbaik dari proses pelatihan dan pengujian, model tersebut dapat digunakan untuk melakukan peramalan jumlah penjualan AMDK. Hasil peramalan JST didernomalisasikan untuk mengetahui nilai aslinya menggunakan rumus (16) Sehingga peramalan penjualan AMDK tahun 2019 adalah pada TABEL VI. Data aktual pada bulan Januari hingga Juni ditampilkan guna melihat dan mengkonfirmasi ketepatan hasil peramalan.

TABEL VI

HASIL PERAMALAN AMDK TAHUN 2019

\begin{tabular}{|l|c|c|c|}
\hline $\begin{array}{c}\text { Periode } \\
\mathbf{2 0 1 9}\end{array}$ & $\begin{array}{c}\text { Data } \\
\text { Aktual }\end{array}$ & Hasil JST & $\begin{array}{c}\text { Hasil Peramalan } \\
\text { (pcs) }\end{array}$ \\
\hline Januari & 2267 & 0,7941 & 2271 \\
\hline Februari & 2008 & 0,7102 & 2019 \\
\hline Maret & 1346 & 0,4908 & 1358 \\
\hline April & 915 & 0,3443 & 917 \\
\hline Mei & 462 & 0,1930 & 462 \\
\hline Juni & 324 & 0,1472 & 324 \\
\hline Juli & - & 0,2852 & 739 \\
\hline
\end{tabular}




\begin{tabular}{|l|c|c|c|}
\hline $\begin{array}{c}\text { Periode } \\
\mathbf{2 0 1 9}\end{array}$ & $\begin{array}{c}\text { Data } \\
\text { Aktual }\end{array}$ & Hasil JST & $\begin{array}{c}\text { Hasil Peramalan } \\
\text { (pcs) }\end{array}$ \\
\hline Agustus & - & 0,1624 & 370 \\
\hline September & - & 0,1613 & 367 \\
\hline Oktober & - & 0,3960 & 1073 \\
\hline November & - & 0,2937 & 765 \\
\hline Desember & - & 0,5005 & 1388 \\
\hline
\end{tabular}

[2] [2] A. Rohman, "Peramalan Penjualan Air Minum Dalam Kemasan (AMDK) PT. Tirta Investama Subang, Jawa Barat," Institut Pertanian Bogor, 2006.

[3] [3] Y. Y. Silfiani and H. Utomo, "Pengaruh Citra Merek, Kualitas Produk Dan Strategi Promosi Terhadap Keputusan Pembelian Produk Amdk Java (Studi Kasus Pada Konsumen Mahasiswa STIE AMA, IAIN Dan UKSW Salatiga) (Yen Yen Silfiani, Hardi Utomo)," Jurnal Among Makarti, vol. 10, no. 20, pp. 37-54, 2017.

[4] [4] A. E. Armi, A. H. Kridalaksana, and Z. Arifin, "Peramalan Angka Inflasi Kota Samarinda Menggunakan Metode Double Exponential Smoothing (Studi Kasus: Badan Pusat Statistik Kota Samarinda)," vol. 14, no. 1, 2019.

Dalam perhitungan hasil peramalan dengan data aktual terdapat beberapa selisih, hal ini normal karena dalam analisis kegiatan peramalan hasil peramalan tidak selamanya sempurna dengan bilangan bulat/real sesuai data aktual dimana hasil peramalan bersifat pendekatan artinya dapat berbeda dengan data aktual. Perhitungan persentasi selisih kesalahan dapat diketahui dengan persamaan rumus persentasi kesalahan (24):

$$
\varepsilon_{t}=\frac{\text { nilai peramalan -nilai aktual }}{\text { nilai aktual }} \times 100 \%
$$

Pada penelitian ini ada perbedaan atau selisih namun tidak begitu signifikan yaitu $2 \%$ dari semua jumlah data aktual yang ada.

\section{KESIMPULAN}

Berdasarkan pelatihan JST backpropagation model arsitektur JST yang digunakan yaitu jaringan multi-layer 12 input layer, 10 hidden layer dan 1 output layer dengan nilai MSE sebesar 0,00043743 dan nilai MAPE $6,88 \%$. Perhitungan peramalan penjualan AMDK dengan menggunakan JST Backpropagation diperoleh hasil peramalan penjualan AMDK 600ml untuk periode 2019 dengan data aktual memiliki selisih. Hasil peramalan penjualan produk AMDK dengan menggunakan metode JST pada penelitian ini terdapat selisih $2 \%$ dengan data aktual. Hal ini normal karena dalam kegiatan peramalan hasil peramalan bersifat pendekatan artinya dapat berbeda dengan data aktual namun dengan selisih yang tidak banyak.

\section{DAFTAR PUSTAKA}

[1] D. Puspitasari, M. Mentari, and W. R. Faldiansyah, "Penerapan Metode Single Exponential Smoothing Menggunakan Pendekatan Adaptif Pada Peramalan Jumlah Pelanggan Dan Kebutuhan Air Pada Pdam Kota," Jurnalti Polinema, pp. 1-6, 2017.

5] [5] M. Nafarin, Penganggaran Perusahaan, Jakarta: Salemba Empat, 2007.

[6] [6] J. Heizer and B. Render, Operation Management, New Jersey: Prentice Hall, 2005.

[7] [7] Marjiyono, B. WA Soedijono, and E. T. Luthfi, "Penggunaan Jaringan Syaraf Tiruan Untuk Meramalkan Permintaan Pada Perusahaan retail," Seminar Nasional Teknologi Informasi dan Multimedia 2018, paper 2.12-7, p.2.

[8] [8] F. Pakaja, Agus Naba, and Purwanto, "Peramalan Penjualan Mobil Menggunakan Jaringan Syaraf Tiruan dan Certainty Factor,' Jurnal EECCIS, vol. 6, no. 1, pp. 23-28, 2012.

[9] [9] H. C. Aprilianto, S. Kumalaningsih, and I. Santoso, "Penerapan Jaringan Syaraf Tiruan Untuk Peramalan Penjualan Dalam Mendukung Pengembangan Agroindustri Coklat di Kabupaten Blitar,” Jurnla Habitat, vol. 29, pp. 129-137, 2018.

[10] [10] A. Revi, Solikhun, and M. Safii, "Jaringan Syaraf Tiruan Dalam Memprediksi Jumlah Produksi Daging Sapi Berdasarkan Provinsi," vol. 2, pp. 297-304, 2018.

[11] [11] N. F. Hasan, K. Kusrini, and H. Al Fatta, "Analisis Arsitektur Jaringan Syaraf Tiruan Untuk Peramalan Penjualan Air Minum Dalam Kemasan," JURTI, vol. 3, no. 1, pp. 1-10, 2019.

[12] [12]F. A. Muqtadiroh, A. R. Syofiani, and T. S. Ramadhani, "Analisis Peramalan Penjualan Semen Non-curah (ZAK) PT. Semen Indonesia (PERSERO) Tbk Pada Area Jawa Timur," Seminar Nasional Teknologi Informasi dan Komunikasi, pp. 308-310, 2015.

[13] [13] A. Kristianto, Jaringan Syaraf Tiruan (Konsep Dasar, Algoritma dan Aplikasi). Yogyakarta: Gava Media, 2004.

[14] [14]A. Hermawan, Jaringan Saraf Tiruan Teori dan Aplikasi, Yogyakarta: Penerbit Andi, 2006.

[15] [15] A. Sudarsono, "Jaringan Syaraf Tiruan Untuk Memprediksi Laju Pertumbuhan Penduduk Menggunakan Metode Backpropagation (Studi Kasus di Kota Bengkulu)," Jurnal Media Infotama, vol. 12, no. 1, pp. 61-69, 2016.

[16] [16]D. Puspitaningrum, Pengantar Jaringan Saraf Tiruan, Yogyakarta: Penerbit Andi, 2006.

[17] [17] Andayani, "Memprediksi Kualitas Lulusan Mahasiswa Menggunakan Algoritma Jaringan Syaraf Tiruan,” M. Kom. thesis, Universitas AMIKOM Yogyakarta, 2018.

[18] [18] M. Febrina, F. Arina, and R. Ekawati, "Peramalan Jumlah Permintaan Produksi Menggunakan Metode Jaringan Syaraf Tiruan (JST) Backpropagation," vol. 1, no. 2, pp. 174-179, 2013.

[19] [19]S. Tias Safitri, Nurkaromah Dwidayati, "Perbandingan Peramalan Menggunakan Metode Exponential Smoothing HoltWinters dan ARIMA," vol. 6, no. 1, pp. 48-58, 2017.

[20] [20]J. J. Siang, Jaringan Syaraf Tiruan dan Pemrogramannya Menggunakan Matlab, Yogyakarta: Penerbit Andi, 2005. 